\title{
Naturally occurring toxins in foods
}

\section{By I. D. Morton, Department of Food Science, Queen Elizabeth College, London $W 87 \mathrm{AH}$}

Toxic materials in foodstuffs can be present naturally or they can occur due to the changes taking place during harvesting, processing or preservation of food. Much has been written in the past about the simpler materials present in foodstuffs which are toxic. I am thinking here of materials such as phytic acid present in the wheat grain and the presence of oxalic acid in the leaves of the rhubarb plant. Less, however, is known about materials present in many of the legumes which require heat treatment before the legumes or the products from the legumes are safe for human consumption.

A modern classification of toxic materials could be as follows: (A) simple compounds present as such in foods; (B) more complicated compounds present in foods which must be and can be removed by treatment before the food is consumed; (C) toxic materials produced by processing and preservation; (D) complicated compounds present in foods which unfortunately are not removed by processing.

We are all accustomed to the use of spices with our foodstuffs. Pepper and salt have been used for centuries. It is, perhaps, not quite so well known that the material present in the ordinary nutmeg is related to lysergic acid and that two whole nutmegs ground up would be sufficient for hallucinations in most people. Many of the essential oils are toxic and a number have been shown to be carcinogenic. Some of the flavouring agents are known also to be carcinogenic. I am thinking here particularly of coumarin which was used extensively at one time and has now been withdrawn. It occurs naturally in the Tonka bean.

Goitrogens are materials which have been known for many years. Iodine deficiency leads to endemic goitre, but not all goitres are caused by lack of iodine in the diet. There are chemicals which interfere with the utilization of iodine or with the functioning of the thyroid gland. Ultimately this will lead to goitre. Compounds present in a number of the Cruciferae species are known to be goitrogenic. Some of the Brassica species possess goitrogens naturally within them. The best known is L-5-vinyl-2-thiooxazalidone. The cyanogenetic glucosides are also naturally present in many foodstuffs including the cassava, one of the food staples of Nigeria and other countries.

Other toxic materials are associated with endemic and spontaneous diseases such as lathyrism. The common vetch Vicia sativa contains cyanoalanine derivatives which are toxic and cause neurotoxicity. Plant species from other 
continents contain a number of toxic compounds. The nut $C y c a d$ circanalis contains the azoxyglycoside cycazine. Cycazine is not toxic to germ-free rats when fed in the diet. Rats with intestinal bacteria, however, have in their gut bacterial enzymes which can hydrolyse the cycazine to yield methylazoxymethanol. This compound is now considered the primary toxic substance from the Cycad nut. Of all the environmental carcinogens, probably the best known and publicized are the polycyclic hydrocarbons present in tobacco smoke and in the atmosphere. It is normally assumed that when these carcinogens have been identified with plants and vegetables, this has denoted contamination from the atmosphere. Evidence has now been presented that synthesis of these compounds such as 3:4-benzopyrene takes place during germination and growth of the soya bean and the lentil seed. The inference is that a certain amount of carcinogen has always been present in man's environment.

In our drinking waters, particularly from shallow surface wells, the presence of nitrates has been reported. Clearly if the presence of nitrate is suspected, the water for drinking must be treated by ion-exchange procedures to remove the $\mathrm{NO}_{3}$ ion. Nitrates in some of our foods can also reach high levels.

\section{(B) Compounds removed by processing}

Soya beans are an important item of the diet for many peoples. The oil which contains linoleic acid, an essential fatty acid is an important dietary constituent. Soya flour was first manufactured commercially in the 1930 in the United States and has been used as a substitute for animal protein. There are a number of toxic substances, now called lectins present in the soya bean. These lectins are inactivated by heat and soya products for human consumption must be subjected to a detailed processing treatment much more rigorous than the processing of material intended for animal consumption. The significant addition is the introduction of a moist heat treatment.

In milk, particularly in colostrum and to a lesser extent in raw milk, a trypsin inhibitor is present. This can explain why people with reduced digestive capacity can only tolerate milk when it is boiled. Eggs possess a trypsin inhibitor as well as the protein avidin, which is an antagonist for biotin. If human beings on a diet low in biotin, are given raw egg white, dermatitis is produced, which can be cured by the addition of biotin.

Among the compounds naturally present in foods after harvesting can be included the mycotoxins produced by mould growth on food. Attention has been directed during the past decade or so to the compound aflatoxin, produced by various strains of Aspergillus flavus which will grow on groundnuts, rice, lentils, wheat and other seeds. Fortunately not all species produce toxic mycotoxin. Several different aflatoxins $B_{1}, B_{2}, G_{1}$ and $G_{2}$ and $M_{1}$ are known. There is now considerable literature on the aflatoxins and their importance should not detract from the other poisonous material produced by other strains of moulds. Much of the scientific work on the aflatoxin derivatives, has been directed to establishing the carcinogenic nature of these compounds. 
The earliest mycotoxin reported was that due to ergot. Epidemics have been recorded as far back as the $15^{\text {th }}$ century and the connection of the malady with a fungoid growth on rye was suspected in the 18 th century. The well known ergot alkaloids are the causative agents. Mushrooms of the Amanita genus such as the Death Cap fungus are not normally regarded as mycotoxin poisoning agents but clearly they do come in this category. Also one could include Muscaria and the Phalloidin species.

Toxicity associated with 'yellowed rice' has been studied in Japan for many years. It was not until after the Second World War, that the cause was traced to several toxin-producing species of Penicillia. Two poisonous compounds Islanditoxin and Luteoskyrin were isolated from culture media. These particular toxins damage the liver and cause haemorrhage. Other mould species in rice produce other and again different toxic compounds. Penicillium toxicarium and Penicillium citroviride, for instance, yield citreoviridin, the yellow fluorescent compound which is a neurotoxin. Citrinin interferes with the kidney function. The Fusaria species produce a number of toxic compounds which cause changes in the blood and the bone marrow. These Fusaria species particularly infect cereals such as millet which have been allowed to over winter on the ground and suitable conditions for toxin formation arise in the spring when the temperatures range from $I^{\circ}$ to $4^{\circ}$.

Facial eczema in sheep is a serious problem to the New Zealand sheep farmer. This was known to be caused by ingestion of perennial rye grass and was traced to infection by the saprophytic fungus Pithomyces chartarum which produces a toxin Sporidesmin. Sporidesmin is a powerful liver poison and the damage caused leads to the accumulation of biliary substances which produce jaundice and photosensitisation. This photosensitisation shows itself in the development of eczematype lesions on those parts of the animals skin not protected from sunlight by hair or wool. Patulin, a common metabolite of a number of mould species, is a neurotoxin.

The common mould Aspergillus ochraceus is known to occur on wheat stored when its moisture content exceeds $60 \%$. It has also been reported as a constituent of the flora used in the fermentation process for the traditional Japanese fish product Katsuobushi. Moreover the organism has been named in a US patent for its ability to produce a desirable change in flavour during the fermentation of coffee. Various research workers have, however, obtained from this organism a highly toxic material Ochratoxin, which has an $\mathrm{LD}_{50}$ in the duckling of $0.5 \mathrm{mg} / \mathrm{kg}$ body-weight. This is comparable with aflatoxin $\mathrm{BI}$.

\section{(C) Toxic materials produced by processing and preservation}

During the past few years, considerable interest and concern has been directed towards the study of nitrosamines. It has long been known that small amounts of saltpetre are indispensible for the formation of the characteristic colour of cured meat. Around 1890 , it was found that the nitrite was in fact the active compound responsible for this colour production. Haldane in his classical publication, 
discussed the mechanism of colour formation. Several decades passed before another characteristic of nitrite was discovered. It is, indeed, a potent inhibitor of various micro-organisms, among them the pathogens. In particular the inhibition of toxin formation by Colostridium botulinum was established. More recently the role of nitrite in cured meat flavour has been recognized.

In a study of heated fats and oils, Professor Lang has shown that frying oils which have been heated beyond their normal usage, will contain a number of compounds which are polymeric in nature and in addition, contain cyclic fatty acids in the triglycerides. There is some concern that these polymeric compounds and the cyclic fatty acids are both toxic to the human. Other work on oils and fats has shown that the naturally occurring phytosterols can act as antioxidants during the heating process. They are, however, destroyed ultimately and the question can be asked 'What type of compound are they transformed into'?

\section{(D) Materials naturally present which cannot be removed}

During the past few years concern has been expressed about the toxins present in seafoods. Marine organisms produce many toxic substances and the modern methods of freezing and shipping throughout the world increase the problem. Many of the marine toxicants are indeed produced by micro-organisms such as the marine algae and reach the edible marine animal consumed by man through the food chain. These particular poisons are difficult to control from the standpoint of public health because of the unpredictable and sporadic occurrence of the organisms producing them. Another important factor is that these poisons are quite stable to heat processing or cooking and are refractory to the action of the digestive enzymes in man. Some species of fish for instance, the Puffers, are intrinsically poisonous and, in Japan, only licensed officials can prepare the Puffer fish for sale. Venoms are localized in special organs and when they do not contaminate the edible portions of marine animals they may be removed or destroyed.

Many species of shellfish have become poisonous through the consumption of toxic marine algae, particularly the Dinoflagellates. Paralytic shellish poisoning is a classic example of a disease caused by the toxic metabolic product produced by Gonyaulax catenella. This organism causes paralytic shellfish poisoning and the poison blocks the sodium influx to nerve cells. It is a water-soluble tetrahydropurine often called Saxitoxin. The 'red tide' poisoning and the Ciguatera poisoning are well documented.

One of the main contaminants of seafood products is the botulinum toxin type E. There are six immunologically distinct types of Clostridium botulinum designated $A-F$ recognized at the present time. Type $E$ organism is particularly adapted to the production of toxin in all fishery products.

Concern has been expressed during the past decade about the contamination by heavy metals of our food materials. The presence of organic metal mercury derivatives in seafood was discovered towards the end of the $1960 \mathrm{~s}$. The mercury poisoning of the seafood in the Minnemata bay in Japan was of course described 
many years ago. We are now much more concerned about the presence of other heavy metals as well as mercury. Cadmium and lead as well as copper are well known to be toxic. To remove these heavy metals from our foods is almost impossible. Of course the use of lead tetraethyl, an antiknock compound in petroleum spirit for motor vehicles, is a case in point. Evidence has been produced showing that food crops grown in the vicinity of an auto road can contain a much higher content of lead than those grown some distance away. The present regulations in this country lay down the lead content for our foodstuffs and are much more strict on the amount which may be present in infant foods compared with the level for normal consumption.

Many other toxic materials have been reported in the literature and no doubt further examples will become known in the future. The following references will give an introduction to this most interesting subject.

\section{REFERENCES}

Bratfette und Siedefette (1974). Muenster: Deutsche Gesellschaft fuer Fettwissenschaft.

Chemicals in Food and Environment. (1975). Br. Med. Bull. 31, 3 .

Crosby, N. T. \& Sawyer, R. (1976). Adv. Fd Res. 22, 1.

Gontzea, I. \& Sutzescu, P. (1968). Natural Antinutritive Substances in Foodstuffs and Forages. Basel: S. Karger.

Krol, B. \& Tinbergen, B. J. (editors) (1974). Proceedings of the Intermational Symposium on Nitrite in Meat Products, Zeist 1973 Wageningen: Centre for Agricultural Publishing and Documentation.

Lis, H. \& Sharon, N. (1973). Ann. Reo. Biochem. 42, 541 .

Morton, I. \& Rhodes, D. N. (editors) (1974). The Contribution of Chemistry to Food Supplies. London: Butterworths.

National Research Council (1973). Toxicants Occurring Naturally in Food. Washington, DC: National Academy of Sciences.

Philp, J. McL. (1970). R. Soc. Hlth. F. 90, 248.

Scheur, P. J. (1969). Fortschr. Chem. org. NatStoffe 27, 322.

Shilo, M. (1972). Progr. Indust. Microbiol. $11,233$.

Spensley, P. C. (1970). R. Soc. Hlth. J. 90, 248.

Walker, R. (1975). J. Sci. Fd Agric. 26, 1735 . 